\title{
Assessment of the precision of smart phones and tablets for measurement of planar orientations: A case study
}

\section{Lucie Novakova $^{1^{*}}$, Terry L. Pavlis ${ }^{2}$}

${ }^{1 *}$ Department of Seismotectonics, Institute of Rock Structure and Mechanics, Academy of Sciences of the Czech Republic, v.v.i., V Holesovickach 41, 182 09, Prague, Czech Republic, phone +420 266009 349, e-mail: lucie.novakova@irsm.cas.cz

${ }^{2}$ Department of Geological Sciences, The University of Texas at El Paso, El Paso, TX 79968, phone (915) 747-5570, e-mail: tlpavlis@utep.edu

\begin{abstract}
Although paper and pencil approaches to geological mapping continue, digital mapping tools are being increasing implemented in field geology. Of particular note is the use of an electronic compass/inclinometer built into tablets and smartphones for obtaining orientation data where an important question is the reliability of these digital devices relative to conventional, analogue compass/inclinometers. This paper deals with this question through detailed tests of two android devices: an Honor 3C smartphone and a Lenovo B8080-F tablet. In order to evaluate potential electronic noise effects the devices were tested in two modes, standard and airplane. Over 14,000 readings from the sensors were collected to evaluate the stability of the sensor's readings and showed that the magnetic sensor in the tablet was unacceptably unstable. Seven geological compass applications were installed on the Honor 3C smartphone and tested against the analogue Freiberg geological compass in a field experiment. During the experiment 25 fractures varying in azimuth and dip were measured
\end{abstract}


using both devices. A high level of disagreement was observed with discrepancies as high as $80^{\circ}$ with azimuthal errors dominant. Analysis of the time series in the data suggest the source of the problem was instability in the magnetic sensor for the smartphone, despite the fact the device passed the initial stability test. Although only two devices were studied these data indicate care must be taken to evaluate compass accuracy on these devices.

Key words: smartphone; compass; fracture; sensor; geology; reliability

\section{Introduction}

Historically, field measurements of the orientation of geological structures ('dip and strike') have been taken with rather simple, mechanical instruments (Clar, 1954), largely unchanged since the science began, and plotted manually on a base map (McCarthy et al., 2009). The geological compass was originally developed from the mining compass that was used for surveying mine tunnels and ore veins. With the advent of smartphones, tablets and PDAs, digital geological compasses also began to appear when manufacturers began to embed magnetic sensors and accelerometers in these devices. A single smartphone now can take the place of an assortment of devices and serve as a basic mapping tool (Pavlis, 2014; Sun et al., 2010). They also come with a number of very desirable functions, such as keyboard/virtual keyboard, camera, recorder, digital compass, GPS receiver, and accelerometer (Weng et al., 2012). Relatively expensive digital compass/inclinometers have also existed for over 10 years (http://www.gsinet.co.jp/english/geoclino/index.html) but have not been used extensively, in part because of the appearance of essentially free devices built into smart phones and tablets.

Despite unprecedented presence of mobile technology and increasing use of the devices, only a few scientific papers focus on digital geological compass measurements (e.g. Lee et al., 
2013, Weng et al., 2012). Nonetheless, the structural geology community has discussed the reliability of the smartphone based structural measurements intensively (e.g. Darren, 2013; Jones, 2014; Kopera, 2014; Rippington, 2010). Thus, the well validated and trusted analogue compass/inclinometer stands in contrast to the speed and comfort provided by digital geology compass applications on smartphones. Geologic compass apps currently available on the android platform are summarized in Table 1. The applications differ in form and functionality, nevertheless, the geological compass function is rather similar and all are based on the same hardware.

Table 1

Here we contribute to the ongoing discussion of use of these aps by presenting results of experiments on two android devices with direct comparison of measurements comparing analogue geological compass measurements and smartphone geological compass application measurements. We begin with a description of direct sensor measurements evaluating their stability in a time series, show results of a field experiment directly comparing measurements, and conclude with an assessment of the results.

\section{Sensor Evaluation in a Smartphone vs. tablet}

\subsection{Methodology}

Two different android devices were tested simultaneously: smartphone (Honor 3C) and tablet (Lenovo B8080-F) (Table 2). The software AndroSensor (Asim, 2015) was used to test the reliability of the sensors of the devices. Magnetic field sensor, accelerometer and 
orientation sensor readings were recorded. Orientation sensor software combines the accelerometer and magnetic field values to provide azimuth, pitch and roll. The device output consists of azimuth, pitch, roll, and magnetic field values as well as $\mathrm{x}, \mathrm{y}, \mathrm{z}$ components (in device coordinates) for the magnetic field (magnetometer) and the gravity field (accelerometer). The azimuth is the angle between magnetic north and device's long axis, pitch is the angle between the device long axis and horizontal, measured in a line contained in the device plane, perpendicular to the long axis and roll is the angle from horizontal, measured along the device long axis (Figure 1). These are standard outputs from these types of devices. Note that variation in azimuth is a variation equivalent to a variation in a compass azimuth measurement whereas the variations in the accelerometer would equate to inclination measurement errors. Variations among the three components in both the magnetometer and accelerometer would reflect variations of individual components within the devices; i.e. a three component magnetometer and three components accelerometer.

\section{Figure 1}

For the tests, devices were placed on a slightly inclined wooden plane each about half a meter from the other. Sampling frequency was $2 \mathrm{~Hz}$. Two modes of the devices were studied standard and airplane mode. Note that airplane mode turns off location functions like cellular, Bluetooth, GPS and WiFi in the devices, and thus, this mode evaluates the role of electronic noise from these functions. Over 14000 readings from each sensor were collected during an hour of recording.

\section{Table 2}

\subsection{Results}


Sensor readings fluctuated over time in both devices but there is a marked distinction between the two devices in the range of fluctuations (Figure 2 and Figure 3). Smartphone Honor 3C (represented by black line) provided quite consistent data with a relatively low level of error at about $\pm 2^{\circ}(2 \sigma)$ in the case of azimuth. Lenovo B8080-F tablet (represented by red line) provided lower quality data with a high level of error, about $\pm 20^{\circ}(2 \sigma)$ in case of azimuth. Pitch data provided by both devices are rather consistent with error less then $\pm 1^{\circ}$. No significant difference was observed between measurements in the different modes - the standard mode and airplane mode (Table 3 and 4).

The $\mathrm{x}, \mathrm{y}, \mathrm{z}$ plots from the magnetometer (middle panels in Figures 2 and 3) show that an important source of variance is individual sensors within the device. In the smartphone (black lines in Figures 2 and 3) the magnetic field measurement varies over less than $2 \mu \mathrm{T}$ in all three components, consistent with the derived azimuth measurements for this device. In contrast, the $\mathrm{y}$ and $\mathrm{z}$ components in the tablet show large variance, particularly the $\mathrm{z}$ component which shows both cyclic fluctuations of $\sim 10 \mu \mathrm{T}$ and abrupt, systematic jumps followed by pseudostability intervals with fluctuations of more than $10 \mu \mathrm{T}$. In this case because the $\mathrm{z}$ measurement is the largest vector component, this nearly $20 \%$ fluctuation in measurement of the magnetic field translates into the large observed fluctuation in the azimuth measurement (Figures 2 and 3).

Other, more subtle features can be seen in these plots that have implications for applications of the devices. Even though the smartphone (black lines in Figures 2 and 3) was generally relatively stable, there are notable transients in the accelerometer outputs, which produce a distinct roll error in one case (Figure 3). Were this transient present during an actual measurement, this error would appear in the data and would be undetectable. Note that one solution in this case would be data averaging of the time series; a feature easily done in software but it is unknown to us if this is done routinely. 
The experiment demonstrates that smartphone Honor 3C should be precise enough for geological compass measurements, particularly if software allows some averaging of the time series output from the device. In contrast, the tablet has such large transients in the time series that it is likely to produce, at the least, noisy data and at the worst, systematic errors; e.g. transient shifts followed by pseudo-stable intervals (Figures 2 and 3) would introduce systematic error over the pseudo-stable interval.

Figure 2

Table 3

Figure 3

Table 4

\section{Field measurement with compasses}

\subsection{Methodology}

A natural outcrop of a Cretaceous marl located a significant distance from cultural noise (power lines, buildings, etc.) was chosen for a series of tests for field measurements. Three series of tests were done:

1) One uncertainty in source of error with these devices is how the data are recorded in software, thus we tested variance among software by repeating measurements on the same surfaces using different software. Twenty-five fractures varying in azimuths and dips were 
marked and measured with the analogue Freiberg geological compass (http://www.fpm.de/index.php?c=1\&s=geokompspiegel) and the smartphone in standard mode. The calibration of the smartphone was done by waving the phone in a figure- 8 pattern (RockGecko, 2015). Seven different geological compass applications (FieldMove Clino, Rock Logger, Geo Lab Tool, Structural Compass, Mining Compass, eGEO Compass GS, Geo clino for Android) installed on the Honor 3C smartphone were tested.

2) To analyse the precision of individual measurements using the same software on surfaces with different orientations, we chose seven fractures with different dips from horizontal to vertical and measured them with the smartphone Honor $3 \mathrm{C}$ running the FieldMove Clino app in standard mode. Each fracture was measured more than hundred times to analyse the variance. One fracture was measured more than a hundred times with an analogue geological compass as a control experiment to analyse the variance in conventional, analogue measurements.

3) Finally, we analyse variance within a data set by measuring more than a hundred various fractures within the same locality, measuring each with analogue geological compass and the smartphone Honor 3C running the FieldMove Clino application in standard mode.

\subsection{Results}

\subsubsection{Test 1}

The results of this test (Tables 5 and 6) show startling variations in measured dip directions among the different apps but less variance in measured dip. For dip directions, standard deviations for the applications vary from $13.0^{\circ}$ to $50.2^{\circ}$. Means for the applications vary from $-8.5^{\circ}$ to $34.8^{\circ}$. The best agreement with the analogue geological compass was provided by the 
"Structural Compass" application. The worse dip direction measurements were recorded by GeoClino for Android. Standard deviation and Mean were calculated at more than $50^{\circ}$ and $30^{\circ}$ respectively.

Dips of the fractures (Table 6) measured on the same fractures show less variance than dip direction, with some notable exceptions. The application Geo Lab Tool was not used for measuring the dips because it does not include this function. Standard deviations for the applications vary from $2.3^{\circ}$ to $23.0^{\circ}$ with means for the applications vary from $-1.6^{\circ}$ to $5.1^{\circ}$ (Table 6). The best agreement with analogue geological compass for dip measurements was provided by the EGEO Compass GS application. The worst result was calculated for application Mining Compass. The difference from the Freiberg measurements was less than $10^{\circ}$ for all applications except Mining Compass where three measurements differed from $65^{\circ}$ to $68^{\circ}$.The standard deviation in Mining Compass variance was calculated at $23^{\circ}$ and mean $5.1^{\circ}$ due in part to these large errors. Standard deviations for the other applications vary from $2.3^{\circ}$ to $4.8^{\circ}$ and means from $-1.6^{\circ}$ to $1.2^{\circ}$.

Considering a tolerance limit for field orientation measurements $\pm 5^{\circ}$, in most of the applications only $20 \%$ of measurements would fit within this allowable error. The best application, Structural Compass, provided $32 \%$ of data within the tolerance limit. In addition, except for FieldMove Clino and Structural Compass, all applications show errors of up to $80^{\circ}$ or even $90^{\circ}$.

Table 5

Table 6

\subsubsection{Test 2}


The second test was done within the same locality. Seven fractures with different dip directions and dips were chosen. The fractures were measured with an analogue Freiberg compass and the same plane was then measured more than a hundred times with the smartphone (Figure 4). Dataset names on each graph refer to the initial analogue compass measurement for the site. For these measurements the application FieldMove Clino was used. This application utilizes build-in declination correction dependant on the GPS location. Based on this location, the linear difference between analogue and digital measurement should be considered at the locality. In the studied locality, the linear difference was $4^{\circ}$.

According to Midland Valley (2014) the smartphone should be placed on the plane and directly measured with the FieldMove Clino app. All the measurements were done according to this suggestion except for the plane 155/77B. The plane $155 / 77$ was measured twice, first as with the rest of the fractures, second with a procedure of waiting until the measured value stayed stable for 10 seconds. The second reading is marked as 155/77B in Figure 4.

Finally, to test the precision of the analogue compass measurements in this setting we chose one fracture and measured it with the analogue compass more than a hundred times (labelled Freiberg in Figure 4). In this case the standards deviation for dip directions of all measurements were calculated at 1.34 , and for dips 0.93 . The maximal differences among the measurements were $5^{\circ}$.

The highest precision was provided by the analogue Freiberg compass and smartphone measurements show surprising variance both within sites and between sites (Figure 4). Statistics for the sites are shown in Table 7. The most surprising result in this test was variance among sites. For example, in the sites 178/19 and 329/39 both the dip and dip direction showed relatively acceptable variances with directions varying $\sim+/-5$ degrees from the measured azimuth and dip variance within +/- 2 degrees or less, and standard deviations 
with a reasonable level (Table 7). At other sites, however, the data are shockingly variable, particularly in dip direction. For example, at site 155/77 (Figure 4) the dip direction varies through nearly 180 degrees in a nearly random fluctuation during the measurement sequence; Site $110 / 55$ shows a similar variation in dip direction as $155 / 77$, but also shows a systematic drift through the time series of the measurements; and 032/66 shows a smaller average variance due to a systematic drift that is nearly sinusoidal during the time series. It is not clear what is causing these variations, but the sequences on each fracture measurement imply the problem is embedded in the electronic device; either random noise, systematic drift, or both.

Figure 4

Table 7

A statistical evaluation was done for all measurements (both analogue and smartphone). Box and whisker plots were calculated for the fractures. Figure 5 shows the maximal and minimal measured value, value of the median and $1^{\text {st }}$ and $3^{\text {rd }}$ quartile. As can be seen qualitatively in Figure 4, the lowest variance is provided by the Freiberg analogue compass. The smart phone measurements of the dip directions of horizontal and subhorizontal fractures provided better results than measurements of subvertical and vertical fractures, but this result could a coincidental result of device stability during those measurements. Measurements of the dips are more or less the same but with a slight increase in variance with increasing dip (Figure 5).

\section{Figure 5}




\subsubsection{Test 3}

To simulate a conventional field measurement campaign we have measured 111 fractures within the same locality with the Freiberg analogue geological compass and the smartphone running the FieldMove Clino app. The FieldMove Clino application was chosen both for ease of use and because it generated good results in test 1 . Rose diagrams for these data show the dip directions and dips of the measured fractures by analogue geological compass (Figure 6A, C) and digital geological compass with FieldMove Clino application (Figure 6B, D).

Figure 6

Like the results in tests 1 and 2, the differences between Freiberg analogue compass measurements and smartphone digital compass application are very high especially for dip directions. Were this a real analysis it is clear that although dip magnitudes could be extracted from these data, the large errors in dip direction produce a dispersion in Figure 6 that would be uninterpretable relative to the analogue measurements (Figure 6A) which show two clear dominant fracture trends.

\section{Discussion}

\subsection{Analysis the Results of these Experiments}

Inspection of the time series recorded from the two Android devices (Figures 2 and 3) illustrate that one underlying issue in using internal sensors within these devices is that some 
sensors are simply poor, unacceptable devices. The abrupt changes in the magnetometer readings in the tablet device produced unacceptable jumps in azimuthal estimates (Figures 2 and 3) that would not only introduce error, but systematic error in measurements that would be unacceptable in any situation. It is tempting to blame electronic noise from the device for some of these issues. The experiments on airplane mode vs. standard mode are indistinguishable, however, suggesting that this internal Rf signal is not the source. Instead, it seems clear that for this tablet, the problem is simply a defective sensor. This demonstrates that some devices will never be acceptable as field measurement devices when equipped with poor sensors like the one in the tablet device. Fortunately, for android devices extreme problems like the tablet can be evaluated with the AndroSensor app. Nonetheless, our other results indicate that test is insufficient to fully evaluate the device.

The results shown in Figures 2 and 3 are not necessarily surprising given the nature of modern electronic devices that contain embedded, generally inexpensive sensors that would be susceptible to high failure rates. What is surprising, however, are the results of the other experiments which used the smartphone device that appeared to contain stable sensors (Figures 2 and 3), yet generated variable, sometimes unpredictable results during the other experiments.

In test 1 , for example, the same surfaces were measured with the same device but using different software, and the result was large variations among the measurements with the smartphone relative to the conventional analogue measurements (Tables 5 and 6). In test 2 , however, we used the same software (FieldMove Clino) for repeat measurements on the same surface; essentially a classic precision test of repeatability among measurements. In this case (Figure 4 and 5) the measurements showed periods of relatively stability at some sites, yet other sites showed extreme variance with dip direction estimates ranging through nearly 180 degrees. Finally, in test 3 we simulated the consequence of using a device of this type on a 
real data set by comparing the data from a conventional analogue device (Figure 6A) to the smart phone (Figure 6C). The result was that had the smart phone been used for data collection, the result would have been uninterpretable relative to a relatively clear bimodal fracture set in the analogue measurements.

We note that the greatest source of variance is from the magnetic sensor, not the accelerometer because the variance in dip estimates is far smaller among all the tests. This observation is not new to this study. Mookerjee et al. (2015) observed similar variations among apps and devices in an ad hoc field test and we have seen similar results testing different sensors that were not embedded in a phone or tablet (Pavlis, unpublished data).

These observations beg the question of what is the source of the variance in azimuth measurements? The source of the error must be the magnetometer that is used for the measurement. Nonetheless, why did tests 1-3 produce such large errors when the device passed the initial tests (Figures 2 and 3)? Perhaps more important, why would software produce different results when all measurements were using a data stream from the same sensors? Without knowing the details of all of the software the answer to the last question is impossible to answer, but it is virtually impossible that all the software contains different bugs contributing to the problem. Instead, the answer almost certainly lies in the sensors themselves. We propose that collectively the results of tests 1-3 suggest that the problem ultimately lies in the magnetometer sensor, and the smartphone device, like the tablet, has sensor problems that were not evident in the initial test (Figure 2).

The best evidence for this interpretation is the data from test 2 . In this test, each site essentially represents a time series for the device such that the sequence number is approximately equivalent to time. With that insight, we could conclude that at the sites $183 / 05 ; 178 / 19$ and 329/39 the magnetic sensor remained relatively stable, generating azimuth estimates with a moderate, but reasonable scatter and with reasonable dip estimates from the 
accelerometer (Figure 4). When the sensor was moved to sites 110/55, 32/66 and 247/85, however, something went wrong with the device and it output large azimuthal errors as well as larger dip errors than sites like $183 / 05$ or $178 / 19$. Site $155 / 77$ and repeat of this site (177/55B) using "wait for stabilization" approach suggests one source of this error may be vibrations in the device or electronic noise related to vibration given that $177 / 55 \mathrm{~B}$ displayed less variance in both azimuth and dip measurements. Nonetheless, using that explanation cannot account for the large systematic change in azimuth measures with time for site 110/55 nor the systematic, sinusoidal errors with time at site 032/66. Those sites suggest, instead, that embedded magnetometer experienced sudden, unexplained drift to produce the observed errors.

This interpretation of results of test 2 provides insight into the observations in test 1 . Specifically, if the magnetometer experienced transients like those seen at sites 110/55, 032/66, and 247/85 in test 2 during test 1 , a similar variance would be observed. However, were this test done alone, the error would be attributed to software, not the underlying hardware. Thus, we suggest that although this smart phone seemed to provide a stable signal during initial tests (Figure 2), over longer time periods the device appears to have magnetometer instabilities that produce dramatic, short period drift that leads to large azimuthal error estimates. An important question, therefore, is would we be able to recognize this problem during a field study by simply monitoring the device? We believe the answer is probably no based on test 3 , where a simulation of a field experiment showed this scatter carries through to a large data set, obscuring an otherwise robust result.

\subsection{Recommendations for field studies}


There are several things that must be kept in mind when making measurements with a compass device, be it analogue or digital. For example, even an analogue compass can yield erroneous readings from interference by magnets, highly magnetic rocks, or ferrous metals. This could include devices like magnetic clasps on phone cases or a GPS unit; e.g. some GPS units are made with a strong magnetic to attach to a car or boat. Electronic compasses, are also potentially subject to error from electronic noise with potential sources including cultural noise from powerlines, or noise from other electronic devices that might include a field computer, watch or GPS unit to name a few. Indeed, in our experience with these devices, many field computers are a major noise source and hidden magnets in devices (e.g. a phone case with a magnetic clip) can all contribute to errors. Neumann et al. (2012) stated that calibration issues and magnetic field interference are the two major influence factors that distort the data which is generated by the digital compass sensor. In particular, it is essential to calibrate the magnetometer, gyroscope, accelerometer combination in the phone before starting measurement (Vaughan et al., 2014). On the other hand not all applications, especially demo, trial or free versions offer a calibration tool. There are a few possibilities, however, for calibrating the digital compass in a smartphone (e.g. ASD, 2014; Bonnet et al., 2009; Midland Valley, 2014).

Although there are many papers about digital geological mapping (e.g. Brodaric, 2004; Clegg et al., 2006; Cracknell and Reading, 2014; Dey and Ghosh, 2008; Pavlis et al., 2010, 2014) and many scientists have switched to digital mapping with smartphones, tablets and computers, there are also geologists advocating the "old school" approach with analogue geological compasses and paper maps. However, such data are not digital (Maerten et al., 2001) which severely limits their use. Jordan et al. (2005) stated that geological mapping with pen and paper is proving inefficient in many respects in the digital age. Currently, digital mapping technology is evolving rapidly through a challenging transitional period between 
lingering use of paper and conversion to promising digital media and electronic mapping methods (Brimhall and Vanegas, 2013). In the forthcoming digital era smartphones and tablets are literally conquering the world, and are only the vanguard of a whole new generation of field studies (e.g. Pavlis and Mason, in press). For seven different digital geological compass applications Google Play declares between 10,000 and 50,000 installations each (see Table 1). With that level of use, the aim of this study was to show how much geologists can trust smartphones while measuring orientation data in field. Reviews on Google Play are mostly positive. The experiment results presented here, however, are not as optimistic as one might expect considering relatively frequent use of smartphones as an occasional substitute for geological compass (Jones, 2014). These results resonate with similar conclusions presented in geology blogs (e.g. http://www.geo.utep.edu/pub/pavlis/digitalmappingwebpages/) and by developers like Midland Valley (http://www.mve.com/digital-mapping) who have long emphasized that users "know their device" before using it for field measurements. The question, however, is how many users actually test their device/application against analogue geological compass or known data. Without such tests our results (e.g. Figure 6) suggest erroneous results are likely.

Unfortunately despite the growing importance of digital compass applications for the Android platform and iOS, only a few scientific papers describe them or evaluate their usage. Lee et al. (2013) developed an application Smart Compass-Clinometer for smartphones. They measured 40 fractures to compare analogue vs. smart phone measurement, and calculated the variance for dip at $1.7^{\circ}$ and for dip direction $2.63^{\circ}$. Similarly, Weng et al. (2012) tested the app GeoTools strike-and-dip function with a side by side comparisons between ADP 2 and a regular Brunton compass in 10 planar surfaces with varying orientations. They concluded that GeoTools application was comparably to the Brunton compass. In contrast, Mookerjee et al. (2015) and results here present a more sobering view for applications of smart phones and 
tablets for making field measurements. Mookerjee et al. (2015) reported large scatter in azimuthal measurements among devices and software, but gave little insight into the source of the problem. The results of our study here suggest strongly the problems are in the hardware itself, and perhaps most sobering, may be unpredictable. That is, in the smartphone studied here initial tests suggested the device should yield acceptable measurements, yet over time the device appeared to generate instabilities of uncertain origin. This result, therefore, echoes Midland Valley's suggestion (http://www.mve.com/digital-mapping) that users should know their device before trusting it as a measurement tool.

Midland Valley (2014) pointed out that digital mapping tools improve the 3D spatial interpretation process by facilitating more analysis and less data management than traditional techniques, especially in the "field office" during the evenings. Indeed, in areas of excellent outcrop our experience suggests field measurements can increase by a factor of 10 using digital compass, and data management is inherently straightforward when the data are georeferenced with a digital mapping system. Thus, when a device is trustworthy, a digital device can vastly improve field efficiency by eliminating transcription of paper notes, etc., and can improve field statistics by large data volumes. Conversely, however, the time saved during measurements is almost insignificant when outcrop is poor and measured structures are sparse, negating the potential benefits of the devices in those cases. Moreover, paper notes never lose power nor are they subject to electronic noise; thus, in some cases analogue techniques will certainly continue for some time.

\section{Conclusions}

There is no doubt popularity of digital techniques in geology increases steadily. Some techniques like remote sensing or satellite imagery processing and GIS are well established 
and mature, while others are less developed. Some digital geology mapping tools like Geopaparazzi or Trimble TeraFlex are still evolving. Some techniques, including smartphone orientation data measurement, are more or less struggling to find its place in the science. A dozen smartphone digital geological compass applications can be found for the Android platform at this time. While we totally agree smartphone digital compasses are fast and comfortable, it is necessary to consider that accuracy and reliability of these applications has yet to be tested properly. Moreover our experiment proved some android digital compass applications work better than others and at least some devices cannot be fully trusted.

We emphasize that our result is not a universal conclusion for each and every smartphone or tablet, yet in the experiments here the observed differences between measurements with analogue geological compass and smartphone digital geological compass in some cases is higher than $80^{\circ}$. The dip direction measurements were found less accurate than dip measurements. The results in general show variability within the measurements (precision) as well as inaccuracy. Because only two devices, both of them Android based, were used in the experiment, it is possible the conclusion might be device as well as platform dependent. On the other hand, we suggest any geologist using a smartphone as a digital geologic compass in the field needs to compare the device and application measurement with an analogue geological compass first and monitor the measured data closely throughout the field day. Considering this result, comprehensive study on the topic is clearly needed across a range of devices. The experiment clearly points out that not every android device with a digital compass can be used as a digital geological compass.

\section{Acknowledgements}


This work was carried out thanks to the support of the long-term conceptual development research organisation RVO: 67985891 to Novakova and NSF EAR-1250388 to Pavlis. We would like to thank I. Horvath for his help with the measurements. We thank the reviewers Dr. K. Ustaszewski and Dr. M. Roach for their constructive reviews, that helped to improve the manuscript.

\section{References}

AsahiKASEI, 2013. AK8963 3-axis Electronic Compass.

ASD, 2014. How To Calibrate Your Digital Compass? [WWW Document]. URL http://www.safety-devices.com/how-to-calibrate-your-digital-compass-a-20.html (accessed 11.8.15)

Asim, F., 2015. AndroSensor [WWW Document]. URL http://www.fivasim.com/androsensor.html.

Bonnet, S., Bassompierre, C., Godin, C., Lesecq, S., Barraud, a., 2009. Calibration methods for inertial and magnetic sensors. Sensors Actuators A Phys. 156, 302-311. doi:10.1016/j.sna.2009.10.008.

Brimhall, G.H., Vanegas, A., 2013. Removing Science Workflow Barriers to Adoption of Digital Geological Mapping by Using the GeoMapper Universal Program and Visual User Interface. Journal of Chemical Information and Modeling 53, 1689-1699. doi:10.1017/CBO9781107415324.004. 
Brodaric, B., 2004. The design of GSC FieldLog: ontology-based software for computer aided geological field mapping. Computers and Geosciences 30, 5-20. doi:10.1016/j.cageo.2003.08.009.

Clar, E., 1954. Ein zweikreisiger Geologen- und Bergmannskompaß zur Messung von Flächen und Linearen. (Mit Bemerkungen $\mathrm{zu}$ den feldgeologischen Messungsarten). Verhandlungen der Geologischen Bundesanstalt 4, 201 - 215.

Clegg, P., Bruciatelli, L., Domingos, F., Jones, R.R., De Donatis, M., Wilson, R.W., 2006. Digital geological mapping with tablet PC and PDA: A comparison. Computers and Geosciences 32, 1682-1698. doi:10.1016/j.cageo.2006.03.007.

Cracknell, M.J., Reading, A.M., 2014. Geological mapping using remote sensing data: A comparison of five machine learning algorithms, their response to variations in the spatial distribution of training data and the use of explicit spatial information. Computers and Geosciences 63, 22-33. doi:10.1016/j.cageo.2013.10.008.

Darren, W., 2013. Should you trust your digital compass? [WWW Document]. Darren Wilkinson Geol. Geochemistry Sci. Comput. Blog. URL https://wilkinsondarren.wordpress.com/2013/06/24/19-update-should-you-trust-yourdigital-compass/ (accessed 11.8.15).

Dey, S., Ghosh, P., 2008. GRDM-A digital field-mapping tool for management and analysis of field geological data. Computers and Geosciences 34, 464-478. doi:10.1016/j.cageo.2007.05.014

Freiberger Prazisionsmechanik, http://www.fpm.de/index.php?c=1\&s=geokompspiegel (accesed 3.2.2017) 
Jones, R., 2014. GV mapper versus Fieldmove [WWW Document]. Tectonics Struct. Geol. Discuss. List. URL https://www.jiscmail.ac.uk/cgi-bin/webadmin?A2=ind1408\&L=geotectonics\&P=R13244\&1=geotectonics\&9=A\&J=on\&d=No+Match\%3BMatch\%3BMatches\& $\mathrm{z}=4$ (accessed 11.8.15).

Jordan, C.J., Bee, E.J., Smith, N., Lawley, R.S., Ford, J.R., Howard, A.S., Laxton, J.L., 2005. The development of digital field data collection systems to fulfil the British Geological Survey mapping requirements 54, 1-6.

Kopera, J., 2014. Some other thoughts from the digital mapping discussion [WWW Document]. Tectonics Struct. Geol. Discuss. List. URL https://www.jiscmail.ac.uk/cgibin/webadmin?A2=ind1410\&L=geo-tectonics \&P=R1494\&1=geotectonics $\& 9=\mathrm{A} \& \mathrm{~J}=\mathrm{on} \& \mathrm{~d}=\mathrm{No}+\mathrm{Match} \% 3 \mathrm{BMatch} \% 3 \mathrm{BMatches} \& \mathrm{z}=4(\operatorname{accessed} 11.8 .15)$.

Lee, S., Suh, J., Park, H., 2013. Smart Compass-Clinometer: A smartphone application for easy and rapid geological site investigation. Computers and Geosciences 61, 32-42.

Maerten, L., Pollard, D.D., Maerten, F., 2001. Digital mapping of three-dimensional structures of the Chimney Rock fault systems, central Utah. Journal of Structural Geology 23, 585-592. doi:10.1016/S0191-8141(00)00142-5.

McCarthy, A., Cosgrave, R., Meere, P., 2009. Use of the iPhone as a geological field tool: practical benefits and technical limitations. Proceedings of the EGU General Assembly. Vienna, Austria. http://meetingorganizer.copernicus.org/EGU2009/EGU2009-11727.pdf.

Midland Valley, 2014. FieldMove Clino Android User Guide.

Mookerjee M., Vieira, D., Chan, M.A., Gil, Y., Pavlis, T., Spear, F., Tikoff, B., 2015. Data Management: Integrating Cyberscience and Geoscience, Earth and Space Science News 96, $\underline{20,18-21 .}$ 
Neumann, R., Peitek, N., Cuadrado-Gallego, J., 2012. GeoPointing on Indoor Maps Enhancing Compass Sensor Accuracy to Enable Interactive Digital Object Selection in Smartphone-Based Map Applications. Proceedings of the $10^{\text {th }}$ ACM International Symposium mobility management and wireless access.

Pavlis, T.L., Langford, R., Hurtado, J., Serpa, L. 2010. Computer-based data acquisition and visualization systems in field geology: Results from 12 years of experimentation and future potential. Geosphere 6, 3, 275-294, doi:10.1130/GES00503.1.

Pavlis, T., 2014. Digital Field Geology \& Digital Geologic Mapping Site [WWW Document]. URL http://www.geo.utep.edu/pub/pavlis/digitalmappingwebpages/ (accessed 19.8.16).

Pavlis, T., Hurtado, J., Langford, R., Serpa, L., 2014. Lessons in modern digital field geology: Open source software, 3D techniques, and the new world of digital mapping. EGU General Assembly Conference Abstracts. Vol. $16 .$.

Pavlis, T.L. and Mason, K.A., (in press) The New World of 3D Geologic Mapping, GSA Today.

Rippington, S., 2010. Digital compass [WWW Document]. Tectonics Structural Geological Discussion List. URL https://www.jiscmail.ac.uk/cgibin/webadmin?A2=ind1004\&L=geo-tectonics $\& \mathrm{P}=\mathrm{R} 1929 \& 1=$ geotectonics $\& 9=\mathrm{A} \& \mathrm{~J}=\mathrm{on} \& \mathrm{~d}=\mathrm{No}+\mathrm{Match} \% 3 \mathrm{BMatch} \% 3 \mathrm{BMatches} \& \mathrm{z}=4($ accessed 11.8.15).

$\begin{array}{lllll}\text { RockGecko, 2015. } & \text { Rocklogger } & \text { [WWW }\end{array}$ http://rockgecko.com/documentation/usage/ (accessed 19.8.16).

STMicroelectronics, 2013. Ultra-compact high-performance eCompass module: 3D accelerometer and 3D magnetometer. 
Sun, F.S., Weng, Y.H., Grigsby, J., 2010. Smartphones for Geological Data Collection - an Android Phone Application. Eos (Washington. DC) 91, 59.

Vaughan, A., Collins, N., Krus, M., Rourke, P., 2014. Recent Development of an Earth Science App - FieldMove Clino. Geophysical Research Abstracts 16.

Weng, Y.-H., Sun, F.-S., Grigsby, J.D., 2012. GeoTools: An android phone application in geology. Computers and Geosciences 44, 24-30.

\section{List of Figures}

Figure 1 Block diagram of the output parameters of a smartphone.

Figure 2 Plots of the sensor readings and the variations recorded during the experiment using the software AndroSensor : the standard mode. Black line - smartphone Honor 3C, red line tablet Lenovo B8080-F. Left plots: data from orientation sensors, middle plots: data from magnetic field sensors, right plots: data from the accelerometers.

Figure 3 Plots of the sensor readings and the variations recorded during the experiment using the software AndroSensor: the airplane mode. Black line - smartphone Honor 3C, red line - 
tablet Lenovo B8080-F. Left plots: data from orientation sensors, middle plots: data from magnetic field sensors, right plots: data from the accelerometers.

Figure 4 Dip directions and dips of the fractures measured by smartphone using the FieldMove Clino application and the Freiberg analogue compass. The label above each graph give the true estimate of the dip direction and dip for each fracture with dip direction as red dots and dip as blue dots for each individual measurement. Note that the dip direction scale is not the same among the graphs, but is the same for all dips. Thus, visual appearance of variance is slightly deceptive among the graphs, but nonetheless, show extreme scatter in dip direction in most cases. The line indicates "correct" dip and dip direction (from analogue measurements).

Figure 5 Box and whisker plots of the measured data sets for dip directions and dips.

Figure 6 A: Rose diagram shows the dip directions (circle) C:dips (quadrant) of the measured fractures by analogue geological compass $(n=111) B$ : Rose diagram shows the dip directions

(circle) D: dips (quadrant) of the measured fractures by digital geological compass with FieldMove Clino application $(\mathrm{n}=111)$.

List of Tables

Table 1 The smartphone applications of geological compasses based on Android platform (data from August 2016). 
Table 2 Specification of the tested android devices (AsahiKASEI 2013, Asim 2015, STMicroelectronics, 2013).

Table 3 Statistics of sensor readings in the standard mode.

Table 4 Statistics of sensor readings in the airplane mode.

Table 5 Dip directions of fractures measured with the analogue geological compass (Freiberg) and various smartphone applications (diff. - difference between Freiberg and application).

Table 6 Dips of fractures measured with an analogue geological compass (Freiberg) and various smartphone applications (diff. - difference between Freiberg and application).

Table 7 Means and standard deviations of dip directions and dips of the fractures measured by smartphone with FieldMove Clino application and Freiberg analogue compass. 


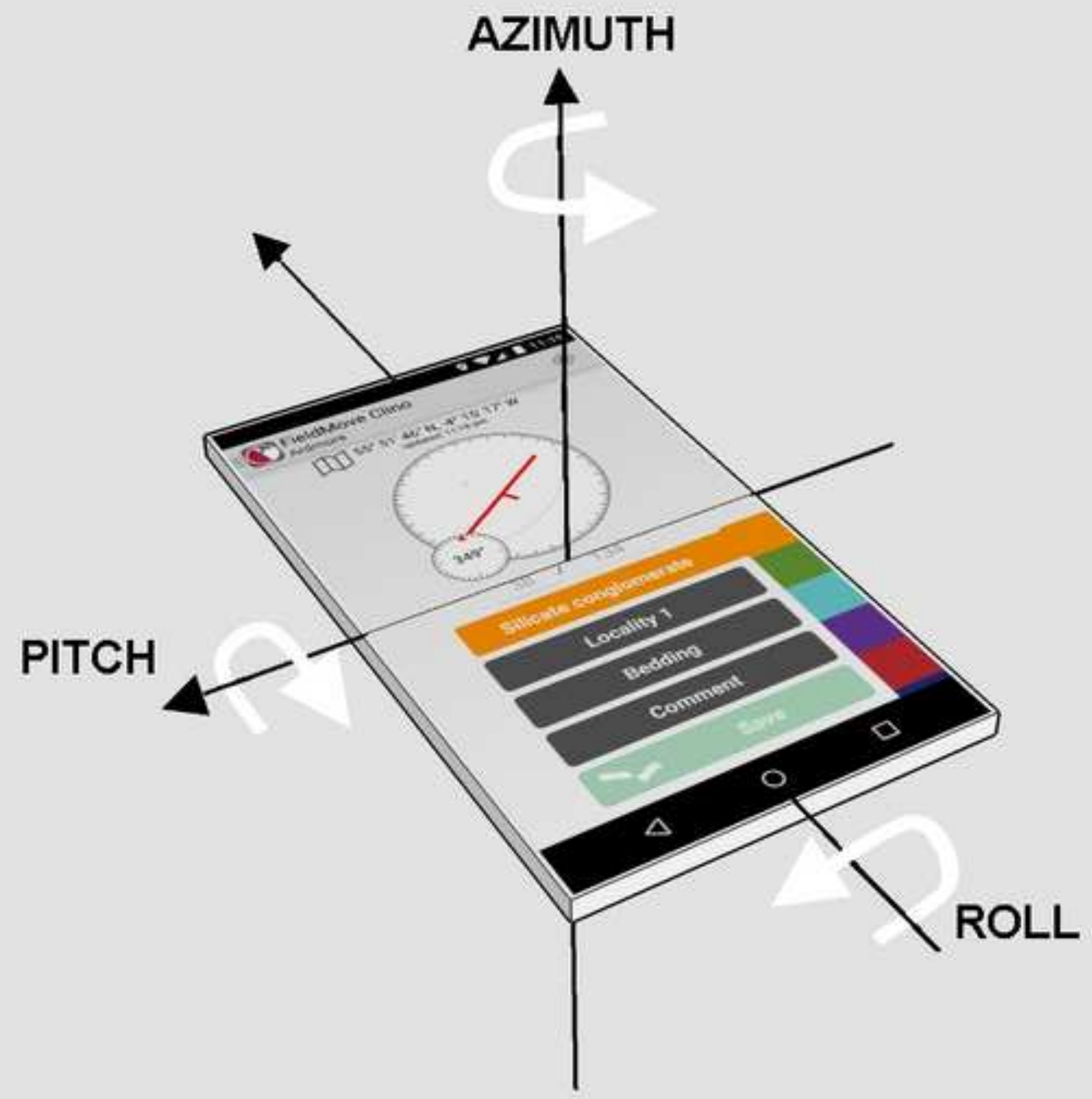



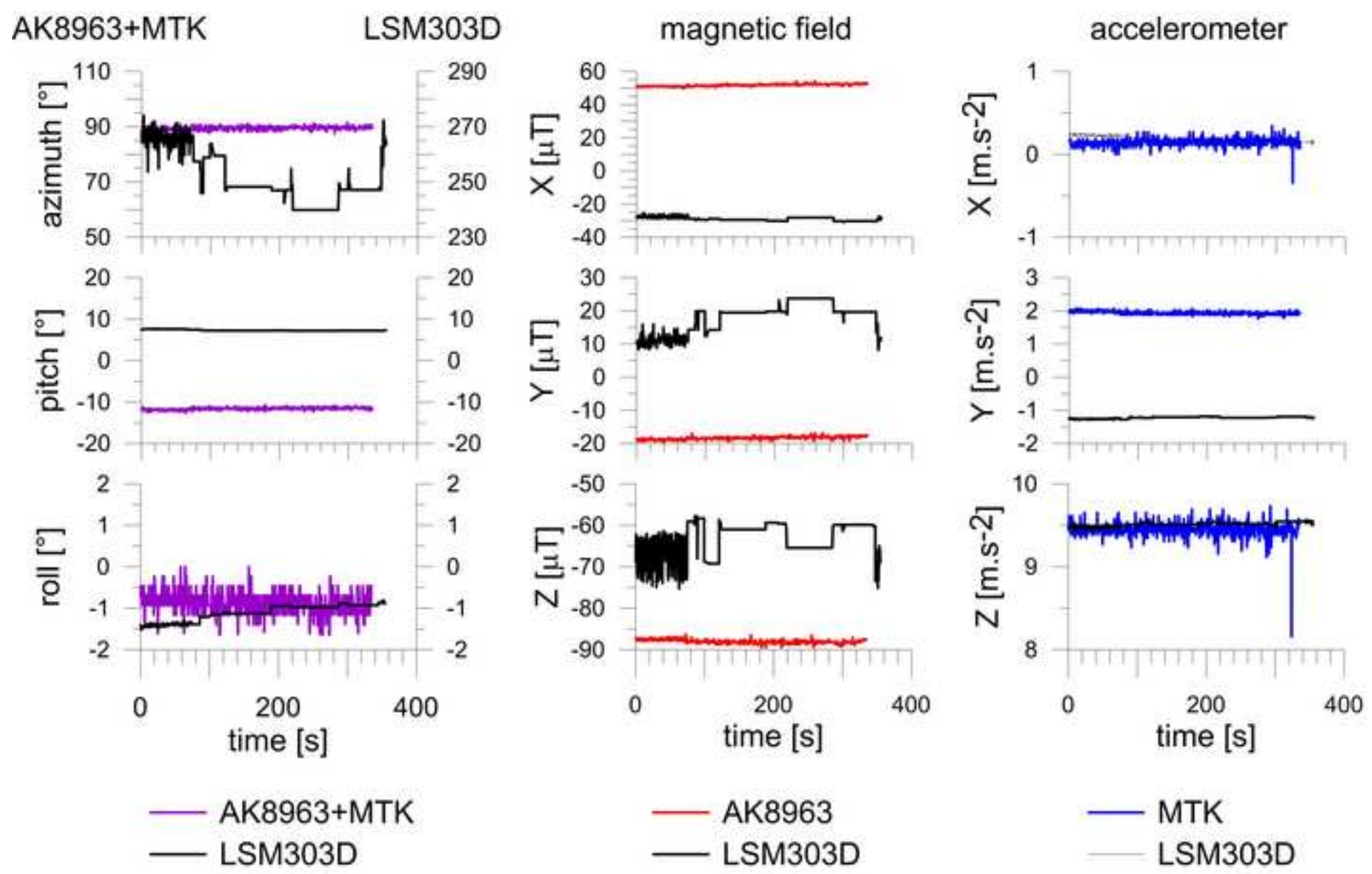

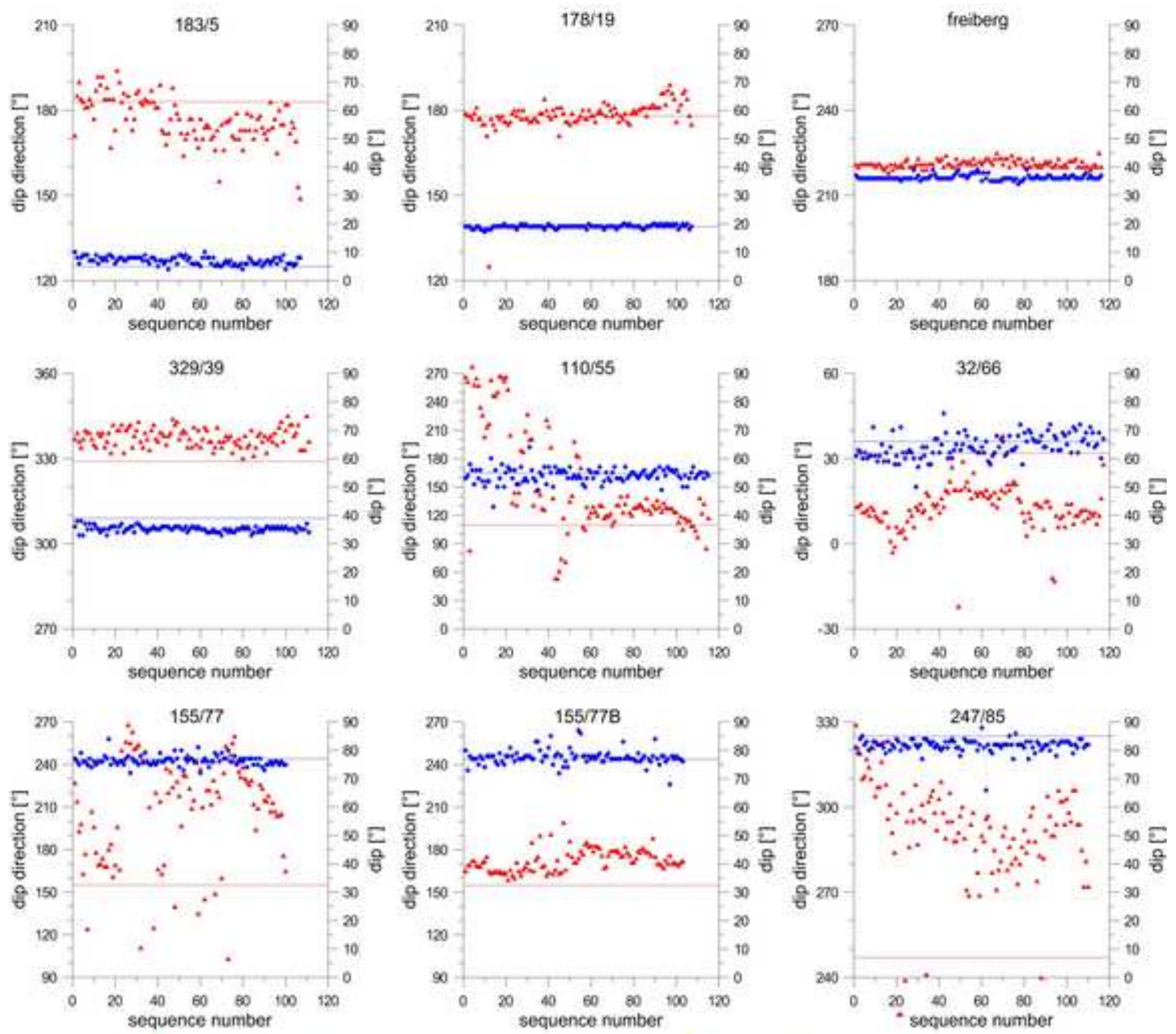

$\mathbf{A}$ dip direction - dip direction by analogue compass

dip - dip by analogue compass 


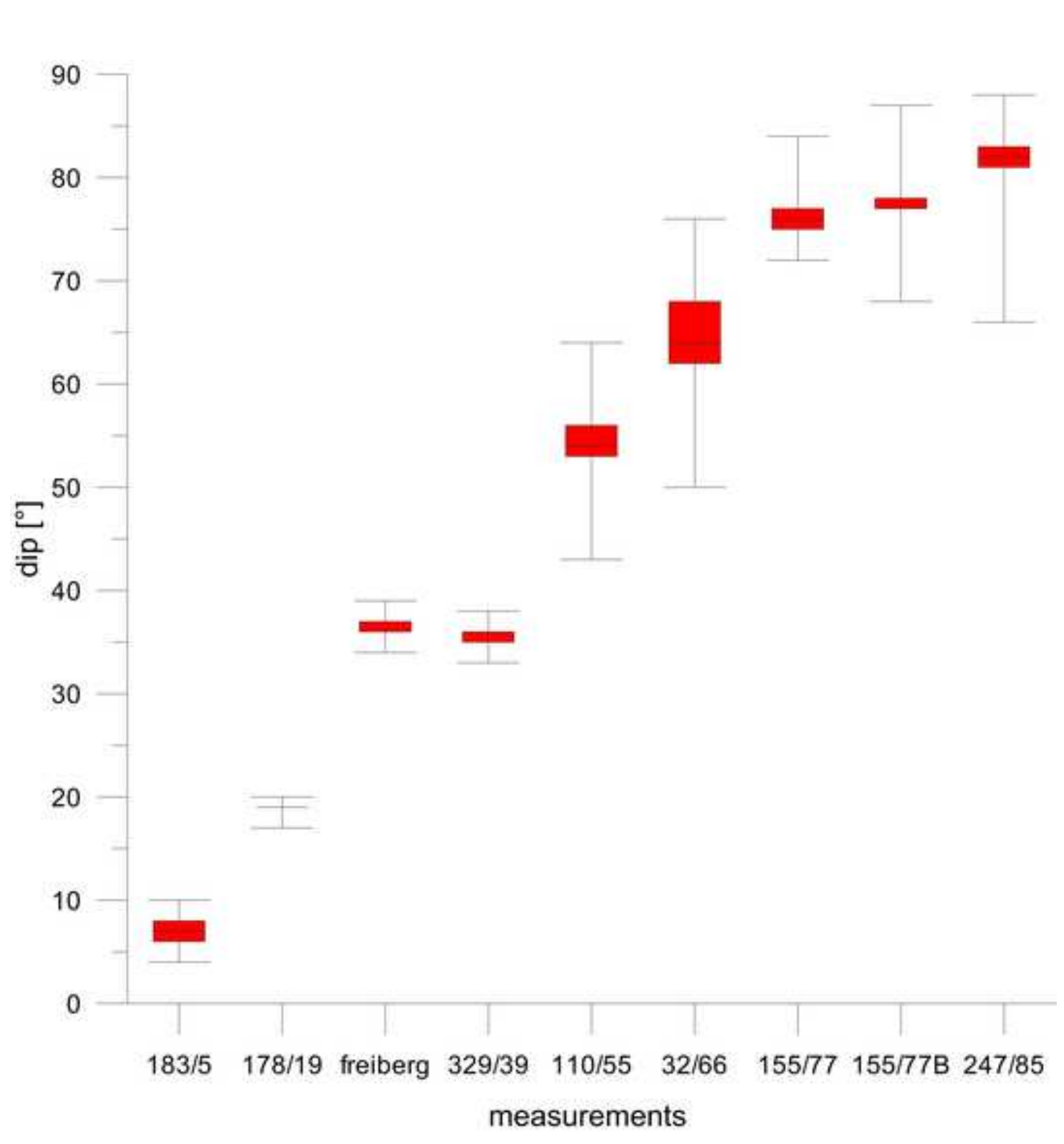

${ }^{*}$ Figure 

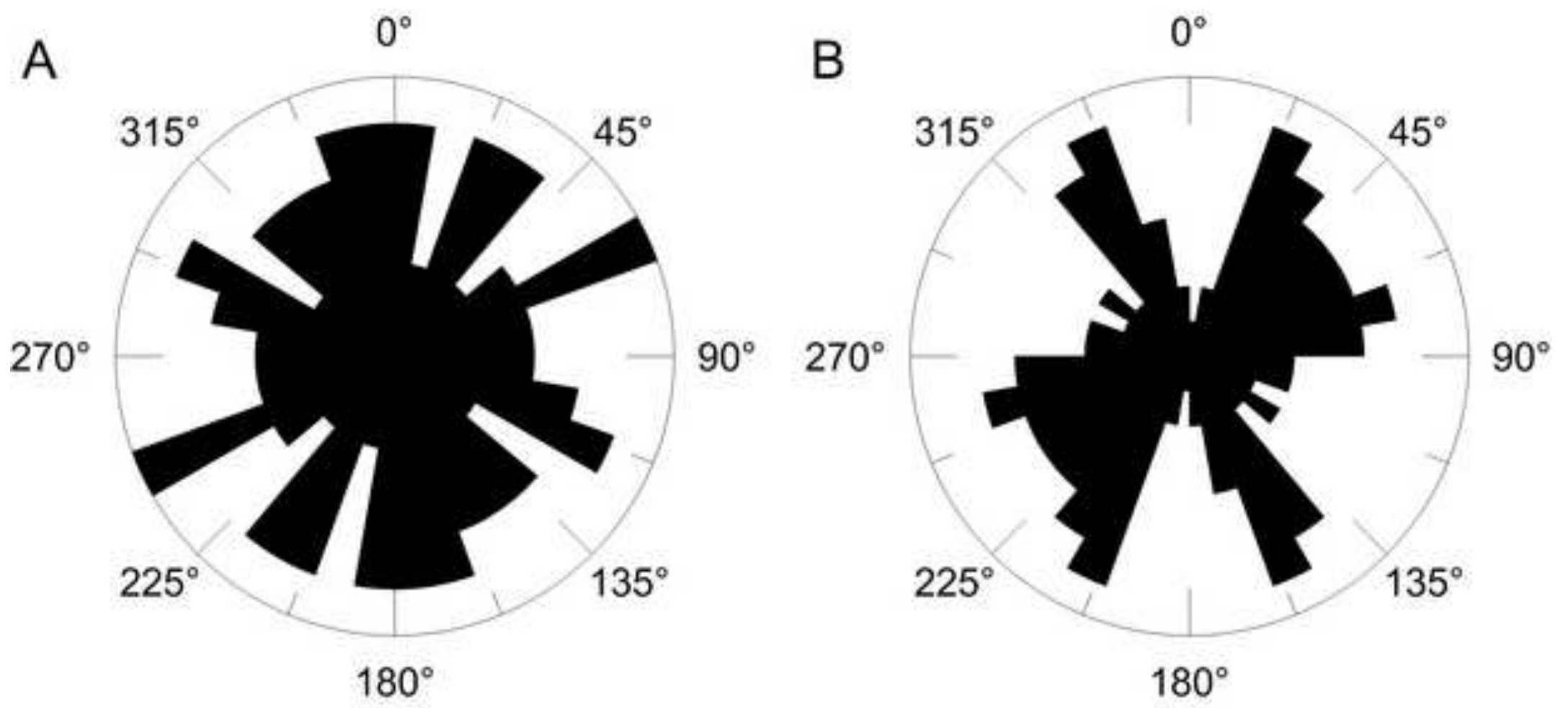

C

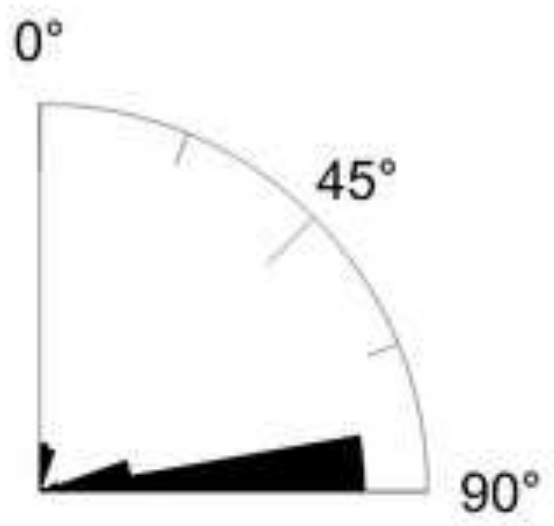

D

$0^{\circ}$

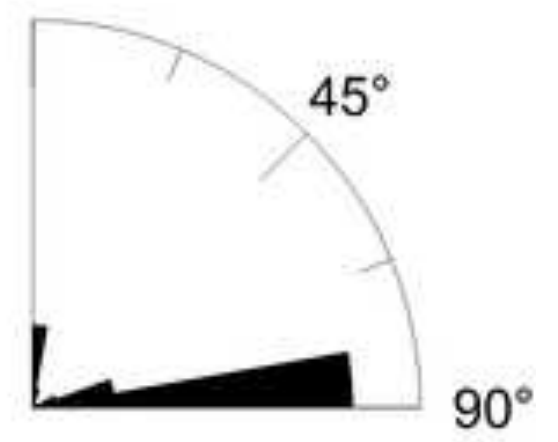


Table 1 The smartphone applications of geological compasses based on Android platform (data from August 2016)

\begin{tabular}{|c|c|c|c|c|}
\hline Name & Developer & Main functions & Instalations & $\begin{array}{l}\text { User review } \\
\text { on Google } \\
\text { Play / } \\
\text { Number } \\
\text { reviewers } \\
\end{array}$ \\
\hline eGEO Compass GS & Marco Foi & $\begin{array}{l}\text { dip-azimuth, dip-angle and dip- } \\
\text { direction, local coordinates }\end{array}$ & $50,000-100,000$ & $3.8 / 227$ \\
\hline eGEO Compass Pro & Marco Foi & $\begin{array}{l}\text { both dips (dip-azimuth and dip- } \\
\text { angle) and lineations of any } \\
\text { surface/linear element }\end{array}$ & $5,000-10,000$ & $4.3 / 40$ \\
\hline FieldMove Clino & $\begin{array}{l}\text { Midland Valley } \\
\text { Exp. Ltd. }\end{array}$ & $\begin{array}{c}\text { traditional hand-held bearing } \\
\text { compass as well as a digital } \\
\text { compass-clinometer for measuring } \\
\text { and capturing the orientation of } \\
\text { planar and linear features in the } \\
\text { field }\end{array}$ & $10,000-50,000$ & $4.5 / 350$ \\
\hline GEO LAB TOOL & $\begin{array}{l}\text { Rafael de Amos } \\
\text { Espinosa }\end{array}$ & $\begin{array}{c}\text { essential tool for cartography, } \\
\text { geotechnical, slope stability, } \\
\text { geodynamics, and more. compass, } \\
\text { inclinometer, gps, altimeter, time } \\
\text { table, camera, annotations }\end{array}$ & $10,000-50,000$ & $4.1 / 92$ \\
\hline GeoClino for Android & GSI CO, Ltd. & strike and dip of a bedding plane & $10,000-50,000$ & $4.0 / 162$ \\
\hline Geocompass & Lucca Innocenti & $\begin{array}{c}\text { a free and simple geological } \\
\text { compass (clinometer), works on } \\
\text { qvga display }\end{array}$ & $5,000-10,000$ & $3.7 / 25$ \\
\hline Geological Compass & THSoft Co., Ltd. & $\begin{array}{c}\text { orientation of geological structures, } \\
\text { analyse the geometry of bedding } \\
\text { planes, joints, and/or metamorphic } \\
\text { foliations and lineations. }\end{array}$ & $10,000-50,000$ & $4.0 / 162$ \\
\hline Geostation & Terrasolum & $\begin{array}{l}\text { dips, dip directions and strikes of } \\
\text { discontinuity sets using the mobile } \\
\text { device as a compass-clinometer }\end{array}$ & $1,000-5,000$ & $3.6 / 17$ \\
\hline GeoToolbox & Filipponi & $\begin{array}{c}\text { geonotes, geocompass, rock mass } \\
\text { classification, q-system, rmr, } \\
\text { database export }\end{array}$ & $100-500$ & $2.0 / 1$ \\
\hline Rocklogger & RockGecko & $\begin{array}{l}\text { orientation of rock outcrops, dip } \\
\text { and dip direction, or dip and strike, } \\
\text { gps and magnetic field } \\
\text { information, along with details on } \\
\text { the rock plane and type }\end{array}$ & $10,000-50,000$ & $4.4 / 279$ \\
\hline
\end{tabular}




\begin{tabular}{|c|c|c|c|c|}
\hline & Major Forms & $\begin{array}{c}\text { strike and dip of planar and linear } \\
\text { features, the longitude, latitude, } \\
\text { altitude, address (if available), and } \\
\text { date and time, magnetic field data, } \\
\text { minerals, individual formations, } \\
\text { rock textures, structures, video } \\
\text { and/or audio, temperature and } \\
\text { pressure, theodolite tool }\end{array}$ & $50,000-100,000$ & $4.2 / 270$ \\
\hline Structural Compass & Apps Medion & $\begin{array}{c}\text { dip, dip direction (magnetic), time } \\
\text { and date of recording, gps } \\
\text { coordinates }\end{array}$ & $1,000-5,000$ & $3.8 / 26$ \\
\hline Russian Mining & Directory \\
Compass & Minerals & $\begin{array}{c}\text { Mining compass for geologists. } \\
\text { They are intended for use in } \\
\text { research of geologists and mining } \\
\text { engineers }\end{array}$ & $1,000-5,000$ & $4.3 / 21$ \\
\hline
\end{tabular}


Table 2 Specification of the tested android devices (AsahiKASEI 2013, Asim 2015, STMicroelectronics, 2013).

\begin{tabular}{|l|l|l|}
\hline \multicolumn{1}{|c|}{ Device } & \multicolumn{1}{|c|}{ Honor 3C } & \multicolumn{1}{c|}{ Lenovo B8080-F } \\
\hline Magnetic field sensor & AK8963 & LSM303D \\
\hline Make & Asahi Kasei Microdevices & STMicroelectronics \\
\hline Range & $\pm 4912 \mu \mathrm{T}$ & $\pm 1200 \mu \mathrm{T}$ \\
\hline Accuracy & $0.6 \mu \mathrm{T}$ & $0.0479 \mu \mathrm{T}$ \\
\hline Accelerometer & MTK & LSM303D \\
\hline Make & MediaTek & STMicroelectronics \\
\hline Range & $\pm 32 \mathrm{~m} . \mathrm{s}^{-2}$ & $\pm 157 \mathrm{~m} . \mathrm{s}^{-2}$ \\
\hline Accuracy & $0.0039 \mathrm{~m} \cdot \mathrm{s}^{-2}$ & $0.0072 \mathrm{~m} \cdot \mathrm{s}^{-2}$ \\
\hline
\end{tabular}


Table 3 Statistics of sensor readings in the standard mode

\begin{tabular}{|c|c|c|c|c|c|c|c|c|}
\hline & \multicolumn{4}{|c|}{ Honor Standad mode } & \multicolumn{4}{|c|}{ Lenovo Standad mode } \\
\hline & Min & Max & Mean & St.dev. & Min & Max & Mean & St.dev. \\
\hline ACCELEROMETER $X\left(\mathrm{~m} \cdot \mathrm{s}^{-2}\right)$ & -0.34 & .34 & 0.14 & 0.06 & 0.1096 & 0.2675 & 0.17 & 0.02 \\
\hline ACCELEROMETER Y $\left(\mathrm{m} . \mathrm{s}^{-2}\right)$ & 1.76 & 2.07 & 1.92 & 0.04 & -1.2959 & -1.181 & -1.21 & 0.02 \\
\hline ACCELEROMETER Z $\left(\mathrm{m} . \mathrm{s}^{-2}\right)$ & 8.16 & 9.73 & 9.45 & 0.13 & 9.4229 & 9.5641 & 9.52 & 0.02 \\
\hline MAGNETIC FIELD X (nT) & 49.74 & 54.12 & 51.92 & 0.65 & -30.95 & -25.33 & -29.51 & 0.86 \\
\hline MAGNETIC FIELD Y (nT) & -19.62 & -16.80 & -18.21 & 0.47 & 8.18 & 23.76 & 19.30 & 3.05 \\
\hline MAGNETIC FIELD Z (nT) & -89.46 & -86.34 & -88.16 & 0.44 & -75.3 & -57.8 & -61.99 & 3.69 \\
\hline ORIENTATION Z (azimuth ${ }^{\circ}$ ) & 267.54 & 271.50 & 269.60 & 0.58 & 59.87 & 94.09 & 68.76 & 6.59 \\
\hline ORIENTATION X $\left(\right.$ pitch $\left.^{\circ}\right)$ & -12.66 & -10.73 & -11.54 & 0.26 & 7.17 & 7.68 & 7.25 & 0.08 \\
\hline ORIENTATION Y (roll ${ }^{\circ}$ ) & -1.64 & 0.00 & -0.88 & 0.23 & -1.52 & -0.81 & -1.03 & 0.14 \\
\hline
\end{tabular}


Table 4 Statistics of sensor readings in the airplane mode

\begin{tabular}{|c|c|c|c|c|c|c|c|c|}
\hline & \multicolumn{4}{|c|}{ Honor Fly Mode } & \multicolumn{4}{|c|}{ Lenovo Fly Mode } \\
\hline & Min & Max & Mean & St.dev. & Min & Max & Mean & St.dev. \\
\hline ACCELEROMETER $X\left(\mathrm{~m} . \mathrm{s}^{-2}\right)$ & -0.04 & 0.27 & 0.10 & 0.06 & -0.04 & 0.20 & 0.04 & 0.05 \\
\hline ACCELEROMETER Y $\left(\mathrm{m}^{\left.-\mathrm{s}^{-2}\right)}\right.$ & 1.76 & 2.03 & 1.92 & 0.04 & -1.60 & -1.18 & -1.22 & 0.05 \\
\hline ACCELEROMETER Z $\left(\mathrm{m} . \mathrm{s}^{-2}\right)$ & 9.16 & 9.73 & 9.44 & 0.07 & 9.48 & 9.58 & 9.54 & 0.02 \\
\hline MAGNETIC FIELD X $(\mathrm{nT})$ & 51.00 & 54.90 & 53.59 & 0.54 & -30.95 & -25.86 & -28.73 & 1.17 \\
\hline MAGNETIC FIELD Y (nT) & -18.78 & -16.02 & -16.80 & 0.49 & 4.21 & 21.3 & 8.01 & 4.78 \\
\hline MAGNETIC FIELD Z (nT) & -89.46 & -86.22 & -87.87 & 0.40 & -80.81 & -60.33 & -70.28 & 4.98 \\
\hline ORIENTATION Z (azimuth ${ }^{\circ}$ ) & 268.13 & 272.54 & 270.92 & 0.83 & 65.84 & 101.61 & 92.14 & 9.94 \\
\hline ORIENTATION X $\left(\right.$ pitch $\left.^{\circ}\right)$ & -12.84 & -10.59 & -11.46 & 0.29 & 7.04 & 7.41 & 7.24 & 0.05 \\
\hline ORIENTATION Y (roll ${ }^{\circ}$ ) & -8.43 & 0.23 & -0.70 & 0.80 & -1.04 & 0.02 & -0.20 & 0.30 \\
\hline
\end{tabular}


Table 5 Dip directions of fractures measured with the analogue geological compass (Freiberg) and various smartphone applications (diff. - difference between Freiberg and application)

\begin{tabular}{|c|c|c|c|c|c|c|c|c|}
\hline & Freiberg & $\begin{array}{c}\text { Field } \\
\text { Move } \\
\text { Clino } \\
\end{array}$ & $\begin{array}{c}\text { Rock } \\
\text { logger }\end{array}$ & Geolab & $\begin{array}{c}\text { Structural } \\
\text { Compass }\end{array}$ & \begin{tabular}{|l} 
Russian \\
Compass
\end{tabular} & Geostru & $\begin{array}{l}\text { Geo } \\
\text { clino } \\
\end{array}$ \\
\hline & dip dir./dip & diff. & diff. & diff. & diff. & diff. & diff. & diff. \\
\hline 1 & $068 / 84$ & 3 & 78 & 2 & -4 & -8 & 4 & 38 \\
\hline 2 & $142 / 88$ & -6 & 53 & 6 & 2 & -5 & -5 & 82 \\
\hline 3 & $261 / 81$ & 47 & -28 & 31 & -14 & 41 & -6 & 76 \\
\hline 4 & $141 / 86$ & -31 & 27 & 4 & -2 & -62 & -7 & -45 \\
\hline 5 & $124 / 88$ & 2 & 84 & 32 & -28 & 54 & -28 & 43 \\
\hline 6 & $116 / 86$ & -66 & -55 & -90 & -10 & -46 & 57 & 85 \\
\hline 7 & $331 / 89$ & -13 & 74 & -26 & -11 & -40 & -49 & 76 \\
\hline 8 & $215 / 89$ & 49 & -6 & 65 & -14 & 45 & 89 & 11 \\
\hline 9 & $139 / 86$ & 52 & 4 & -41 & -19 & -51 & -9 & 71 \\
\hline 10 & $124 / 05$ & 34 & 33 & 2 & -11 & -11 & -28 & -64 \\
\hline 11 & $049 / 64$ & -14 & -83 & -11 & -11 & -79 & -3 & -3 \\
\hline 12 & 096/07 & -11 & 67 & -10 & -32 & -4 & 32 & 86 \\
\hline 13 & 084/01 & -14 & 64 & -15 & -6 & -8 & 44 & 72 \\
\hline 14 & $084 / 75$ & 1 & 84 & 6 & -7 & -1 & -1 & 80 \\
\hline 15 & $052 / 84$ & 39 & 3 & 48 & -3 & 78 & -78 & 42 \\
\hline 16 & $084 / 86$ & 23 & 32 & -73 & -3 & 61 & -3 & 56 \\
\hline 17 & 068/03 & 9 & 60 & -10 & 8 & -6 & -3 & 66 \\
\hline 18 & $058 / 85$ & -54 & 55 & -47 & -3 & 45 & 9 & 26 \\
\hline 19 & $327 / 89$ & -65 & -43 & -83 & -3 & -61 & 22 & 87 \\
\hline 20 & $256 / 89$ & -46 & -33 & -51 & -4 & -57 & -24 & 74 \\
\hline 21 & $057 / 02$ & 27 & 65 & 1 & 9 & 4 & -38 & -18 \\
\hline 22 & $223 / 89$ & 57 & 31 & 56 & -9 & -69 & 2 & -37 \\
\hline 23 & $315 / 89$ & 33 & 6 & 59 & -14 & 50 & -15 & 54 \\
\hline 24 & $040 / 86$ & -16 & -74 & -43 & 11 & -29 & 80 & -9 \\
\hline 25 & $340 / 89$ & -32 & -28 & -24 & 36 & -11 & -40 & -80 \\
\hline $\begin{array}{l}\text { st. } \\
\text { deviation }\end{array}$ & & 35.9 & 50.2 & 41.9 & 13.0 & 44.4 & 37.5 & 50.2 \\
\hline mean & & 0.3 & 18.8 & -8.5 & -5.7 & -6.8 & 0.1 & 34.8 \\
\hline
\end{tabular}


Table 6 Dips of fractures measured with an analogue geological compass (Freiberg) and various smartphone applications (diff. - difference between Freiberg and application)

\begin{tabular}{|c|c|c|c|c|c|c|c|}
\hline & Freiberg & $\begin{array}{c}\text { Field } \\
\text { Move } \\
\text { Clino } \\
\end{array}$ & $\begin{array}{l}\text { Rock } \\
\text { logger }\end{array}$ & $\begin{array}{c}\text { Structural } \\
\text { Compass }\end{array}$ & $\begin{array}{l}\text { Russian } \\
\text { Compass }\end{array}$ & Geostru & Geo clino \\
\hline & dip dir./dip & diff. & diff. & diff. & diff. & diff. & diff. \\
\hline 1 & $068 / 84$ & 5 & 5 & 4 & 4 & 3 & 6 \\
\hline 2 & $142 / 88$ & 3 & 6 & 6 & 4 & 3 & 6 \\
\hline 3 & $261 / 81$ & -3 & -4 & -13 & -2 & -4 & -4 \\
\hline 4 & $141 / 86$ & 0 & 0 & -1 & 2 & 0 & 0 \\
\hline 5 & $124 / 88$ & 0 & 1 & 0 & 3 & 1 & 2 \\
\hline 6 & $116 / 86$ & -1 & -1 & -5 & -1 & -1 & -4 \\
\hline 7 & $331 / 89$ & 8 & 7 & -6 & 5 & 3 & 4 \\
\hline 8 & $215 / 89$ & 3 & 2 & -1 & 2 & 0 & 0 \\
\hline 9 & $139 / 86$ & -2 & 1 & 0 & 0 & 0 & 1 \\
\hline 10 & $124 / 05$ & 0 & 2 & 0 & 1 & 1 & 2 \\
\hline 11 & $049 / 64$ & 6 & 6 & 4 & 65 & 4 & 7 \\
\hline 12 & 096/07 & -3 & -2 & 6 & 6 & 4 & -2 \\
\hline 13 & $084 / 01$ & -7 & -6 & 1 & -68 & 0 & -6 \\
\hline 14 & $084 / 75$ & 9 & 6 & 3 & 68 & 5 & 8 \\
\hline 15 & $052 / 84$ & 2 & -4 & -8 & 10 & -3 & -4 \\
\hline 16 & $084 / 86$ & -3 & 1 & -4 & 1 & -2 & -1 \\
\hline 17 & $068 / 3$ & -4 & -4 & 2 & 0 & 0 & -3 \\
\hline 18 & $058 / 85$ & -1 & 1 & -2 & -1 & -2 & -1 \\
\hline 19 & $327 / 89$ & 2 & 1 & -3 & 1 & -1 & -1 \\
\hline 20 & $256 / 89$ & 5 & 5 & -7 & 6 & 4 & 5 \\
\hline 21 & $057 / 02$ & -4 & -3 & -1 & 1 & -1 & -5 \\
\hline 22 & $223 / 89$ & 0 & 2 & 0 & 4 & 2 & 3 \\
\hline 23 & $315 / 89$ & 0 & 1 & 0 & 4 & 0 & 2 \\
\hline 24 & $040 / 86$ & 8 & 4 & -12 & 2 & 3 & 4 \\
\hline 25 & $340 / 89$ & 7 & 3 & -4 & 10 & 2 & 2 \\
\hline $\begin{array}{l}\text { st. } \\
\text { deviation }\end{array}$ & & 4.2 & 3.5 & 4.8 & 23.0 & 2.3 & 3.9 \\
\hline mean & & 1.2 & 1.2 & -1.6 & 5.1 & 0.8 & 0.8 \\
\hline
\end{tabular}


Table 7 Means and standard deviations of dip directions and dips of the fractures measured by smartphone with Field Move Clino application and Freiberg analogue compass.

\begin{tabular}{|c|c|c|c|c|}
\cline { 4 - 5 } Measurements & mean dip dir mean dip & st. dev. dip dir & st. dev. dip \\
\hline $183 / 05$ & 179 & 7 & 19.32 & 1.32 \\
\hline $178 / 19$ & 178 & 19 & 6.08 & 0.60 \\
\hline Freiberg $221 / 36$ & 231 & 36 & 1.34 & 0.93 \\
\hline $329 / 39$ & 338 & 35 & 3.20 & 1.01 \\
\hline $110 / 55$ & 152 & 54 & 54.73 & 2.58 \\
\hline $032 / 66$ & 12 & 64 & 7.64 & 4.12 \\
\hline $155 / 77$ & 208 & 76 & 36.23 & 1.75 \\
\hline $155 / 77 \mathrm{~B}$ & 173 & 78 & 7.53 & 2.59 \\
\hline $247 / 85$ & 300 & 82 & 27.92 & 2.32 \\
\hline
\end{tabular}

